\title{
Downregulation of Siah1 promotes colorectal cancer cell proliferation and migration by regulating AKT and YAP ubiquitylation and proteasome degradation
}

\author{
Zhiyuan Xiao ${ }^{1,2,3 \dagger}$, Zhigang Wei ${ }^{4 \dagger}$, Danling Deng ${ }^{1,2,5 \dagger}$, Zhe Zheng ${ }^{1,2}$, Yali Zhao ${ }^{1,2}$, Shenglu Jiang ${ }^{1,2}$, \\ Dan Zhang ${ }^{1,2}$, Ling-Jie Zhang ${ }^{1,2}$, Mingmei Fan ${ }^{1,2}$, Siqi Chen ${ }^{1,2}$, ShuYang Wang ${ }^{1,2}$, Yanqing Ding ${ }^{1,2^{*}}$, Yaping Ye $\mathrm{Y}^{1,2^{*}}$ \\ and Hongli Jiao ${ }^{1,2^{*}}$
}

\begin{abstract}
Background: Colorectal cancer (CRC) is one of the most common malignant tumors in the world. Siah E3 ubiquitin protein ligase 1 (Siah1) has been identified as a tumor suppressor gene and plays an important role in the development of malignant tumors. However, the potential role and molecular mechanism of Siah1 in the development and progression of CRC is still unclear.

Methods: To explore the role and molecular mechanism of Siah 1 in the development and progression of CRC, we examined the expression of Siah1 in CRC tissue samples and analyzed its association with progression and prognosis in CRC. In addition, overexpression and knockdown of Siah1 was used to investigate its activity in CRC cells. We also use bioinformatics to analyze and verify the significant roles of Siah1 in critical signaling pathways of CRC.

Results: We found that the expression of Siah 1 was significantly downregulated in CRC tissues, and low expression of Siah1 was associated with aggressive TNM staging and poor survival of CRC patients. Moreover, we revealed that overexpression of Siah1 in CRC cells markedly inhibited CRC cell proliferation and invasion in vitro and in vivo, while knockdown of Siah1 enhanced CRC cell proliferation and invasion. Furthermore, we found that Siah1 prohibited cell proliferation and invasion in CRC partially through promoting AKT (the serine-threonine protein kinase) and YAP (yes associated protein) ubiquitylation and proteasome degradation to regulate the activity of MAPK(mitogen-activated protein kinase 1), PI3K-AKT (phosphatidylinositol 3-kinase-the serine-threonine protein kinase) and Hippo signaling pathways.
\end{abstract}

Conclusions: These findings suggested that Siah1 is a novel potential prognostic biomarker and plays a tumor suppressor role in the development and progression of CRC.

Keywords: Colorectal cancer, Siah1, Ubiquitylation, Proliferation, Migration

*Correspondence: dyqsmu@126.com; 149941225@qq.com; 25048195@qq.com

†Zhiyuan Xiao, Zhigang Wei and Danling Deng contributed to the work equally and should be regarded as co-first authors

${ }^{1}$ Department of Pathology, Nanfang Hospital and School of Basic Medical Science, Southern Medical University, Guangzhou 510515, China

Full list of author information is available at the end of the article

\section{Background}

Colorectal cancer (CRC) is one of the most common malignant tumors in the world. It is known that many oncogenes and tumor suppressor genes are involved in the development of CRC, such as Kirsten rat sarcoma viral oncogene homolog (KRAS) [1], $\beta$-catenin,

c) The Author(s) 2020. This article is licensed under a Creative Commons Attribution 4.0 International License, which permits use, sharing, adaptation, distribution and reproduction in any medium or format, as long as you give appropriate credit to the original author(s) and the source, provide a link to the Creative Commons licence, and indicate if changes were made. The images or other third party material in this article are included in the article's Creative Commons licence, unless indicated otherwise in a credit line to the material. If material is not included in the article's Creative Commons licence and your intended use is not permitted by statutory regulation or exceeds the permitted use, you will need to obtain permission directly from the copyright holder. To view a copy of this licence, visit http://creativeco mmons.org/licenses/by/4.0/. The Creative Commons Public Domain Dedication waiver (http://creativecommons.org/publicdomain/ zero/1.0/) applies to the data made available in this article, unless otherwise stated in a credit line to the data. 
adenomatous polyposis coli (APC) [2], tumor protein p53 (TP53) and so on [3, 4]. Although many diagnostic and therapeutic strategies have advanced, the clinical outcome and prognosis of CRC remains unsatisfactory. Therefore, it is necessary to explore more potential biomarkers involved in the initiation and development of CRC in order to predict the prognosis for this disease.

Ubiquitination plays an important role in the development of colorectal cancer. It regulates cellular biological processes through the ubiquitin critical proteins. Siah E3 ubiquitin protein ligase 1, also known as Siah1, is a human homolog of Drosophila seven in absentia (sina) gene. The Siah1 protein is a member of the E3 ubiquitin ligase family, which are highly conserved in evolution. E3 ubiquitin ligase enzymes can promote the ubiquitination process by enhancing the ubiquitination of target proteins. Siah1 can bind to a variety of target proteins, thereby triggering their ubiquitylation and degradation by the ubiquitin-proteasome pathway. These target proteins include NcoR (nuclear receptor co-repressor), TRAF (TNF receptor associated factor), $\beta$-catenin, c-Myb (c-MYB proto-oncogene), APC, Kid and so on [5-8].

Previous studies have shown that Siah1 is a target of MiRNAs [9-11] and other proteins [12] that are likely to affect the occurrence and progress of tumor [13]. Recent studies [14-18] have found that Siah1 plays an important role in promoting apoptosis under hypoxic conditions or by the P53-induced pathway, and during the process of tumor development, Siah1 behaves as a tumor suppressor. It has been reported that Siah1 is downregulated or even deficient in different tumors [19-21]. More importantly, Siah1 mediates the ubiquitination of target proteins that regulate general functions necessary for tumorigenesis and the progression of cancer, such as cell growth arrest, apoptosis, and DNA repair, etc. [22-25]. These findings indicate that Siah1 plays an important role in the development of malignant tumors. However, the potential role and molecular mechanism of Siah1 in the development and progression of CRC is still unclear.

Uncontrolled, unlimited and accelerated multiplication is one of the most fundamental biologic behaviors of cancer cells. Many pathways are involved in the proliferation and apoptosis of malignant cells, such as P53 [26], AKT $[27,28]$ and Hippo signaling pathways, which are also implicated in the control of cell proliferation and death [29]. The ubiquitination of some key proteins leads to abnormal regulation of these signaling pathways. However, the ubiquitination substrates of Siah1 in the progression of CRC remain unclear.

In this study, we aimed to detect the expression of Siah1 was in CRC tissues, analyze the relationship between Siah1 expression and clinicopathological parameters, and explore the biological function and molecular mechanism of Siah1 in the tumorigenesis and development of CRC.

\section{Methods \\ Patients and specimens}

This study analyzed 170 formalin-fixed paraffin-embedded human colorectal carcinoma samples, which were histopathologically and clinically diagnosed at Nanfang Hospital, Southern Medical University between 2010 and 2015. Prior approval was obtained from the Institutional Research Ethics Committee. Clinical information of the samples is summarized in Additional file 1: Table S1. The 50 freshly collected colorectal cancer tissues and paired normal mucosal tissues were frozen and stored in liquid nitrogen until use.

\section{Immunohistochemistry}

Immunohistochemistry (IHC) staining and scoring were done as previously described $[30,31]$ using Rabbit antiSiah1 (Abcam, \#ab69638, dilutions: 1:200) or Rabbit antiKi-67 (Bioworld, \#bs1454, dilutions: 1:200). For details, please see Additional file 2: Additional materials and methods.

\section{Cell cultures}

The human CRC cell lines (SW480, HCT116) were originally purchased from the American Type Culture Collection (Manassas, VA, USA). They were cultured in RPMI-1640 medium (Gibco, Grand Island, NY, USA) containing $10 \%$ fetal bovine serum (FBS; PAA Laboratories, Pasching, Austria) at $37^{\circ} \mathrm{C}$ with $5 \% \mathrm{CO}_{2}$.

\section{Vector construction and retroviral infection}

The Siah1 construct was generated by subcloning PCR amplified full-length human Siah1 cDNA into pEZLv105. For silencing of Siah1, 2 short hairpin RNA (shRNA) sequences were cloned into the GV248 vector to generate GV248-RNAi(s). Sequences of shRNA primers are provided in Additional file 1: Table S3. Retroviral production and infection were performed as previously described [32]. Stable cell lines expressing Siah1 or Siah1-shRNA were selected for 10 days with $1.0 \mathrm{mg} / \mathrm{mL}$ puromycin.

\section{RT-QPCR and Western blot analyses}

RT-QPCR(Realtime-Quantitative reverse transcription polymerase chain reaction) and Western blot were done as previously described [33]. RT-QPCR primers were designed using Primer 5.0 software. Sequences of the primers are provided in Additional fie 1: Table S3.

Western blot was performed according to standard methods as described previously [34]. Anti-Siah1 
(Abcam, \#ab69638, dilutions: 1:200), anti-phospho-AKT (Cell Signaling Technology, \#C31E5E, dilutions: 1:200), anti-AKT (Cell Signaling Technology, \#11E7, dilutions: 1:1000), anti-JNK (Bioworld Technology Inc., \#BS1544, dilutions: 1:200), anti-phospho-JNK (Bioworld Technology Inc., \#BS4322, dilutions: 1:1000), and anti-YAP (Cell Signaling Technology, \#8418, dilutions: 1:200) antibodies were used for Western blot. A mouse monoclonal anti- $\alpha$-Tubulin antibody (Tianjin Sungene Biotech Co, \#KM9007, dilutions: 1:10,000) was used as an internal control to confirm equal loading of proteins.

\section{Tumorigenesis in nude mice}

Xenograft tumors were generated by subcutaneous injection of cells $\left(2 \times 10^{6}\right.$ for SW480/Lv105 and SW480/Siah1) on the hind limbs of 4-6 weeks old Balb/C athymic nude mice (nu/nu; the Animal Center of Southern Medical University, Guangzhou, China $\mathrm{n}=6$ for each group). Subsequent treatment of all mice was performed as previously described [35]. We counted five randomly selected high-power fields and calculated the average percentage of stained cells among the total cell as the Ki-67 (Bioworld, \#bs1454, dilutions: 1:200) index in subsequent IHC staining [36]. The data were calculated using paired t test.

\section{Statistical analysis}

All statistical analyses were performed using SPSS version 20.0. Mann-Whitney $U$ and Chi square tests were used to analyze the relationship between Siah1 expression and the clinicopathologic features of CRC. Survival curves were plotted by using the Kaplan-Meier method and compared using the log-rank test. Univariate survival distribution was compared by the log-rank test. Functional experiments (MTT and wound-healing assays) were analyzed via one way ANOVA. $\mathrm{P}<0.05$ was considered significant.

\section{Accession numbers for the data sets}

The GEO database (GSE38832) was used to analyze the relationship between the expression of Siah1 and the 5 -year overall survival of the CRC patients.

\section{Biological information analysis}

A computational gene co-expression search engine was used to analyze the relationship between the co-expression of Siah1 and the related signaling pathways. SearchBased Exploration of Expression Compendium (SEEK) (http://seek.princeton.edu), which provides biologists with a way to navigate the massive human expression compendium that now contains thousands of expression datasets, to analyze co-expression of Siah1 in CRC data provided by the search engine, then KEGG analysis
(DAVID Bioinformatics Resources 6.8, http://david.abcc. ncifcrf.gov/) was performed using the top 500 most negative-correlated genes.

\section{Results}

Siah1 is downregulated in CRC tissues, and its expression was associated is progression and poor prognosis in CRC

Western blot was used to detect the expression of Siah1 in 10 CRC tissues. The result showed that Siah1 was significantly downregulated in CRC tissues (T) compared with their paired adjacent noncancerous tissues (N) (Fig. 1a). The result from RT-PCR revealed that the Siah1 mRNA level was also downregulated in CRC tissues (Fig. 1b, Additional file 3: FigureS1A, B and Additional file 4: Figure S2A). To analyze the relationship between the expression of Siah1 and the clinicopathological parameters, the expression of Siah1 protein was detected by immunohistochemistry (IHC) in 170 paraffin-embedded archived CRC tissues. Siah1 protein was significantly decreased or not detected in $67.6 \%(115 / 170)$ cases of CRC tissues, whereas among the remaining 55 (32.4\%) cases displayed high Siah1 expression (Fig. 1c, Additional file 1: Table S1). The Mann-Whitney U test was used to analyze the relationship between Siah1 expression and clinicopathologic features of CRC. As showed in Additional file 1: Table S1, Siah1 expression was strongly correlated with $\mathrm{T}$ classification $(\mathrm{P}=0.005), \mathrm{N}$ classification $(\mathrm{P}=0.003)$, and $\mathrm{M}$ classification $(\mathrm{P}=0.030)$. We further confirmed these data by Spearman correlation analysis (Additional file 1: Table S2), and the coefficients of correlation between Siah1 expression and T classification, $\mathrm{N}$ classification, $\mathrm{M}$ classification were $-0.218(\mathrm{P}=0.004)$, $-0.196 \quad(\mathrm{P}=0.013), \quad-0.230 \quad(\mathrm{P}=0.003)$ and -0.166 $(\mathrm{P}=0.030)$, respectively. Kaplan-Meier survival analyses of five published CRC data sets (GSE38832) [37] suggested that patients with high Siah1 levels had significantly better overall survival $(\mathrm{P}<0.001)$ and disease-free survival $(P=0.001$, Fig. $1 d)$ than patients with low Siah1 levels. These results indicated that Siah1 expression was closely associated with the progression and prognosis of CRC.

\section{Exogenous overexpression of Siah 1 inhibits the proliferation and migration of human CRC cells}

To evaluate whether Siah1 plays a role in the proliferation of human CRC cells, medium expression cell lines HCT116/SW480 were selected to follow up subsequent functional study (Additional file 4: Figure S2C), stable Siah1 expressing CRC cell lines SW480/Siah1 and HCT116/Siah1 were established (Fig. 2a). The results of MTT assays revealed that, compared to the control group, Siah1 overexpression decreased the growth rate of SW480/Siah1 and HCT116/Siah1 (Fig. 2b; SW480/Siah1: 

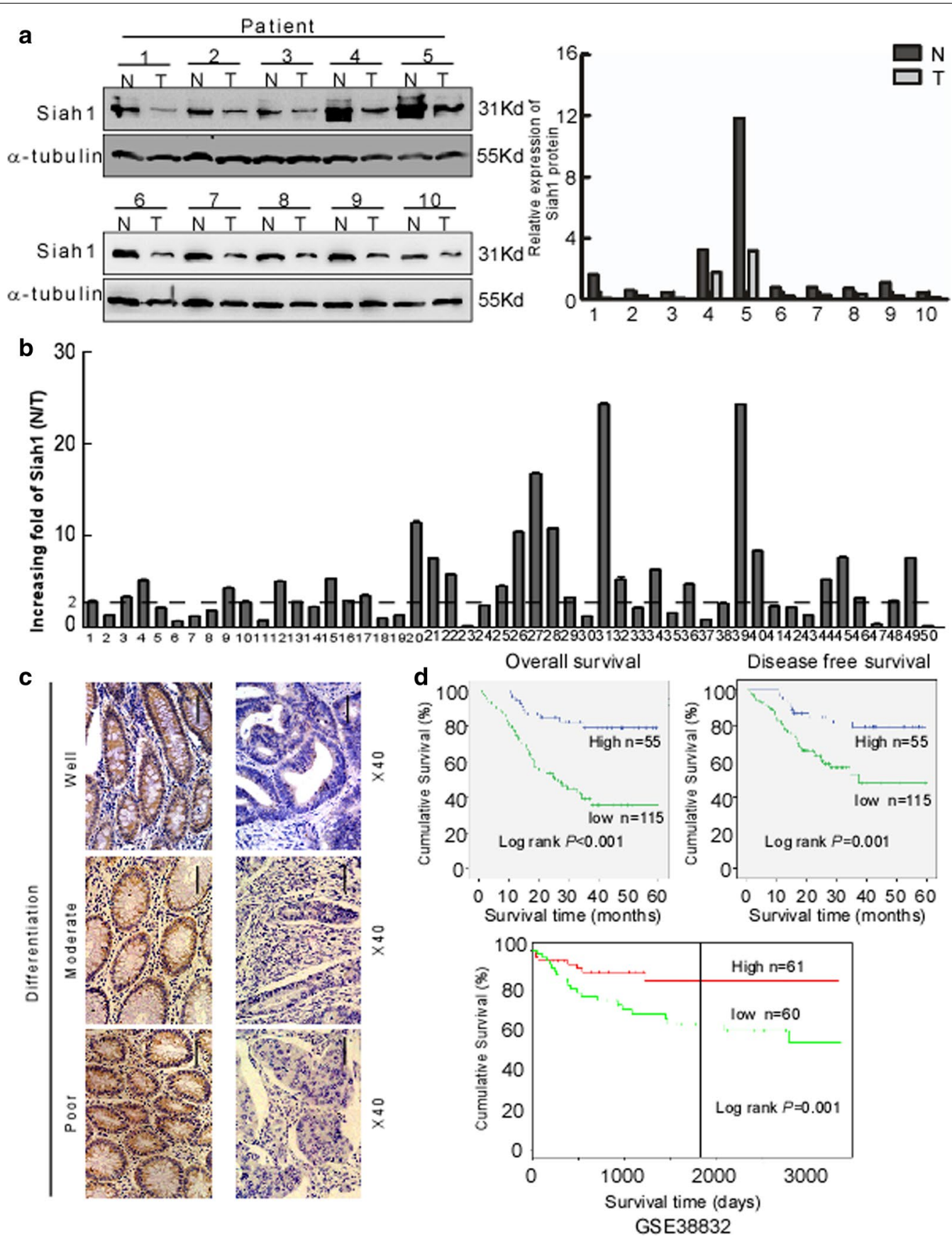

Fig. 1 Decreased expression of Siah1 indicates poor clinical prognosis in colorectal cancer. a Expression of Siah1 protein in ten primary CRC (T) and adjacent noncancerous tissues $(\mathrm{N}$ ) paired from the same patient, assessed by Western blot (left). The protein expression levels were quantified by comparing the gray level of each band using Quantity one Software (right). $\mathbf{b}$ Average $N / T$ ratio of Siah1 mRNA expression by RT-QPCR( $n=50)$. The expression of mRNA levels was normalized with GAPDH. Error bars represent mean \pm SD calculated from 3 parallel experiments. c Representative images of Siah1 expression in normal intestinal epithelium and CRC specimens with different differentiation examined by IHC. Siah1 was positively detected in normal intestinal epithelial cells (left), whereas it was only weakly (middle) or negatively (right) detected in CRC cells. Scale bar: 50 um. $\mathbf{d}$ Influence of Siah1 expression level on overall survival (upper left) and disease-free survival (upper right) of CRC patients by Kaplan-Meier analyses. Green, patients with low Siah1 expression ( $n=115)$; blue, patients with high expression of Siah1 $(n=55)$. GSE38832 showed the effect of Siah1 expression level on overall survival of CRC patients(lower) 

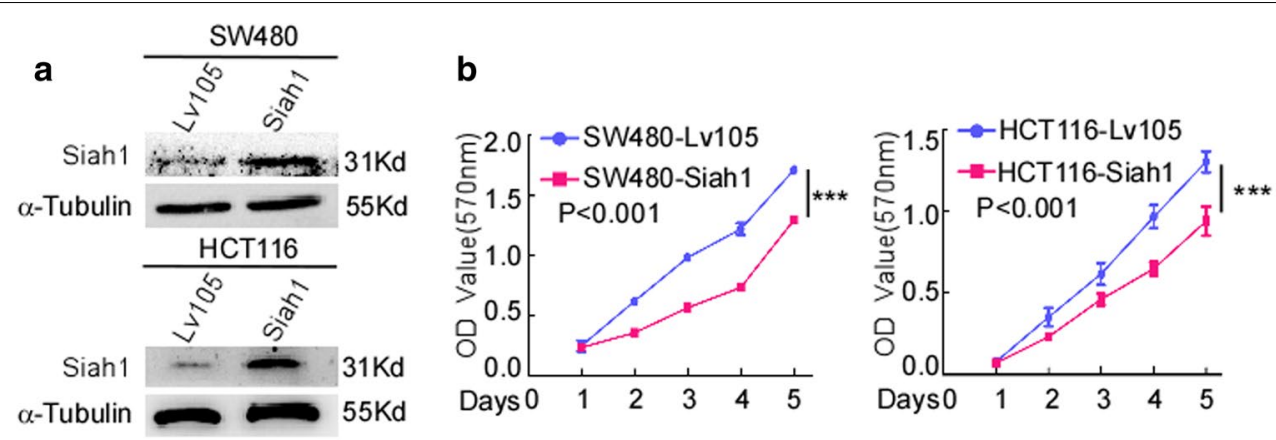

C

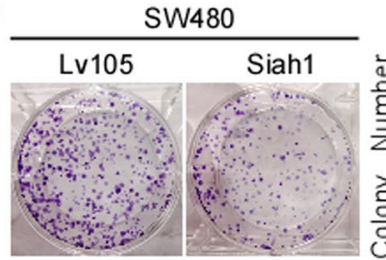

HCT116

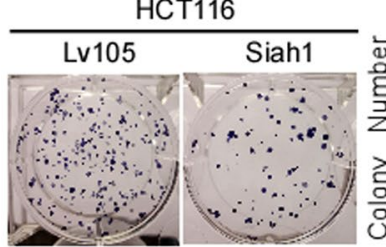

e

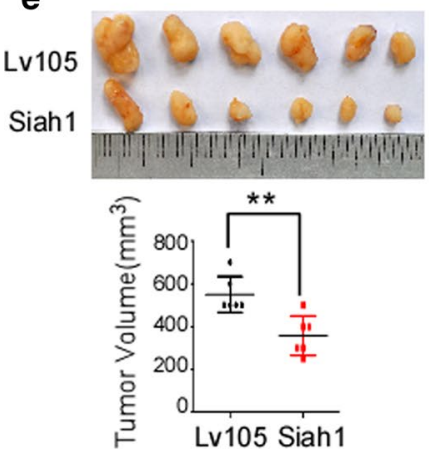

d

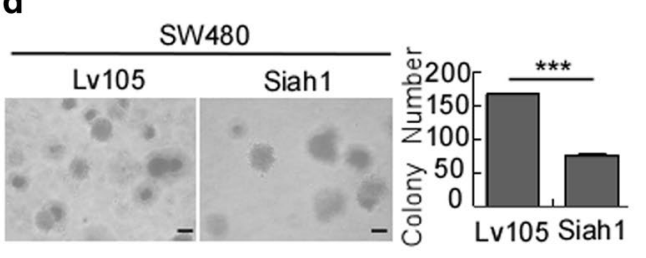

Lv105 Siah1
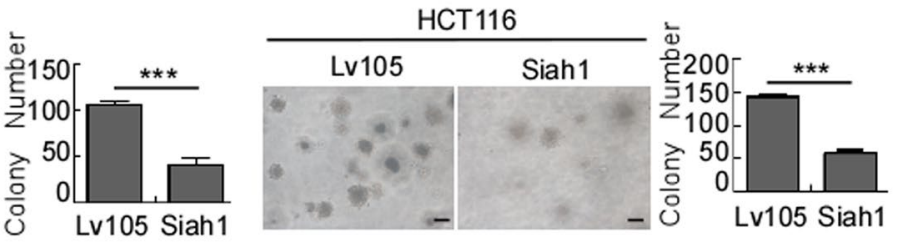

f

SW480

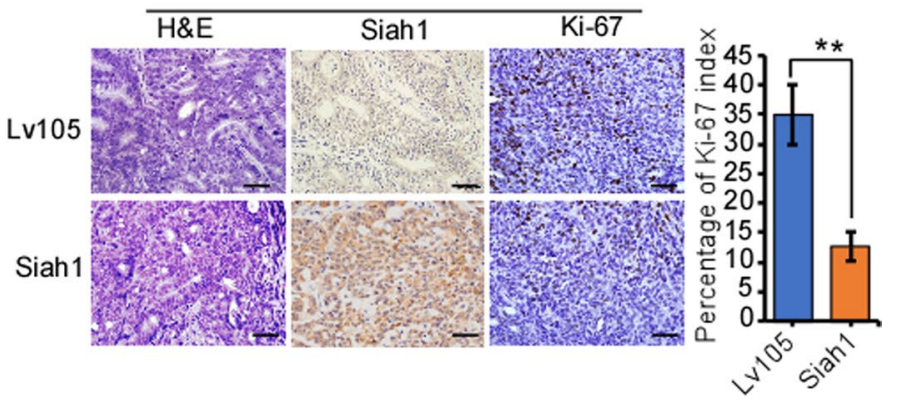

Fig. 2 Overexpression of Siah1 inhibits proliferation in CRC cells. a Ectopic expression of Siah1 in SW480 and HCT116 cells, analyzed by Western blot. a-Tubulin was used as a loading control. b, c Ectopic expression of Siah1 inhibits cell proliferation, as determined by MTT assays (b) and colony formation assays (c). d Overexpression of Siah1 inhibits SW480 and HCT116 cell growth in soft-agar assays. Only colonies containing $>50$ cells were counted. Each error bar represents the mean \pm SD from 3 independent experiments. * $P<0.05$, **P<0.01, ${ }^{* * *} P<0.001$. Scale bar: $50 \mu$ m. e SW480/Lv105 and SW480/Siah1 cells $\left(2 \times 10^{6}\right)$ were injected to the hindlimbs of nude mice $(n=6)$. The volumes of tumors were measured on the indicated days. Data points are displayed as the mean tumor volumes \pm SD (lower panel). The upper panel shows tumors after inoculation. $\mathbf{f}$ The tumor histological sections were under H\&E staining and IHC staining using an antibody against Siah1 and Ki-67 (left), right panel shows average percentage of staining cells among the total cell as the Ki-67 index. Scale bar: $50 \mu \mathrm{m}$

$\mathrm{P}<0.001$; HCT116/Siah1: $\mathrm{P}<0.001)$. As demonstrated in colony formation assays, SW480/Siah1 and HCT116/ Siah1 cells formed fewer colonies compared with the control groups (Fig. 2c; SW480/Siah1: P<0.05; HCT116/ Siah1: $\mathrm{P}<0.001)$. We next investigated the effect of Siah1 on the tumorigenesis of CRC cells by soft-agar assay. The results indicated that Siah1 overexpression significantly inhibited the growth of SW480 and HCT116 cells, as displayed by the reduction in colony number and size on soft agar (Fig. 2d, SW480/Siah1: $\mathrm{P}<0.0001$; HCT116/ Siah1: $\mathrm{P}<0.0001)$. To confirm this effect in vivo, we conducted tumorigenesis assays in nude mice by subcutaneous injection of SW480/Lv105 and SW480/Siah1 cells. Compared to control cells, SW480/Siah1 cells showed 
slower tumor growth and remarkably smaller tumor volume (Fig. 2e) $(n=6, P<0.05)$. In addition, we also found that the tumors formed by SW480/Siah1 cells exhibited much lower proliferation indexes (the positive rate of Ki-67) than the tumors formed by SW480/Lv105 cells (Fig. 2f). We also verified the same results with HCT116 cell lines (Figure S2A and S2B) $(n=6, P<0.05)$. The results of wound-healing assays and transwell chamber invasion assays showed that overexpression of Siah1 in SW480 and HCT116 inhibited the migratory speed and number of CRC cells (Fig. 3a, b; transwell: SW480/Siah1: $\mathrm{P}<0.0001$; HCT116/Siah1: $\mathrm{P}<0.05)$, compared with control cells.

\section{Exogenous knockout of Siah1 promotes the proliferation and migration of human CRC cells}

To further confirm the role of Siah1 in the proliferation of CRC cells, we knocked down endogenous Siah1 expression in SW480 and HCT116 CRC cells by using specific short hairpin RNAs (Additional file 4: Figure S2 and Additional file 5: Figure S3; Fig. 4a). MTT assays and colony formation assays (Fig. 4b, c; MTT: SW480GV248/SW480-Siah1-shRNA: $\quad \mathrm{P}<0.001 ; \quad$ HCT116GV248/HCT116-Siah1-shRNA: $\quad \mathrm{P}<0.001$; colony formation assays: SW480-GV248/SW480-Siah1-shRNA: $\mathrm{P}<0.0001 ; \quad$ HCT116-GV248/HCT116-Siah1-shRNA: $\mathrm{P}<0.005)$ demonstrated that silencing of Siah1 expression caused evidently more rapid growth in SW480 and HCT116 cells, compared with the control cells. Moreover, knockdown of endogenous Siah1 in SW480 and HCT116 cells caused a striking increase in colony number and an obvious growth of colony size on soft agar (Fig. 4d; SW480-GV248/SW480-Siah1-shRNA: $\mathrm{P}<0.0001 ; \quad$ HCT116-GV248/HCT116-Siah1-shRNA: $\mathrm{P}<0.0001)$. Moreover, we also conducted tumorigenesis assays in nude mice by subcutaneous injection of SW480/ GV248 (negative control) and SW480/Siah1-shRNA (exogenous knockout) cells. In contrast to control cells, SW480/Siah1-shRNA cells showed faster tumor growth and remarkably bigger tumor volume (Fig. 4e) $(n=6$, $\mathrm{P}<0.05)$. In addition, we also found that the tumors formed by SW480/Siah1 cells exhibited much higher proliferation indexes (the positive rate of Ki-67) than the tumors formed by SW480/GV248 (Fig. 4f). We also verified the same results with HCT116 cell lines (Additional file 5: Figure $\mathrm{S} 3 \mathrm{C}$ and $\mathrm{D})(\mathrm{n}=6, \mathrm{P}<0.05)$. In addition, the results of wound-healing assays and transwell chamber invasion assays also demonstrated that endogenous knockout of Siah1 enhanced migratory ability of SW480 and HCT116 cells, as indicated by an increase in migratory speed and number of CRC cells (Fig. 5a, b; transwell: SW480-GV248/SW480-Siah1-shRNA: $\mathrm{P}<0.001$; HCT116-GV248/HCT116-Siah1-shRNA: P<0.0001).
Siah1 regulated the activity of the MAPK, PI3K-AKT and Hippo pathways through the ubiquitination of AKT and YAP in CRC cells

We analyzed the negative co-expression of Siah1 in CRC, and KEGG (Kyoto Encyclopedia of Genes and Genomes) signaling pathway analysis was conducted (http://seek. princeton.edu/). The results of biological information revealed that MAPK, Hippo, Wnt, and VEGF (Vascular Endothelial Growth Factor A) signaling pathways were significantly enriched (Fig. 6a). We further detected the expression of genes associated with these pathways through Western blot. Siah1 remarkably decreased the levels of ERK (Extracellular regulated protein kinases), phosphorylated ERK (p-ERK), AKT, phosphorylated AKT (p-AKT), JNK (c-Jun N-terminal kinase), phosphorylated JNK (p-JNK) and Yap (Fig. 6b), whereas silencing of endogenous Siah1 dramatically increased expression levels of ERK, phosphorylated ERK (p-ERK), AKT, phosphorylated AKT (p-AKT), JNK, phosphorylated JNK (p-JNK) and Yap (Fig. 6c). These results indicated that Siah1 inhibits proliferation through regulating the activity of the MAPK and Hippo signaling pathways (Additional file 5: Figure S3E and F).

Siah1 acts as a member of the E3 ubiquitin ligase family, which is involved in the ubiquitylation and degradation of some specific proteins. We next detected the interaction between Siah1 and AKT or YAP by Co-Immunoprecipitation (Co-IP) in SW480. As Fig. 6d shows, Siah1 interacted with AKT and YAP. Furthermore, ubiquitylation detection assay was used to examine poly-ubiquitylation levels of AKT and YAP. The results demonstrated the K48-polyubiquitination levels of AKT and YAP were higher in Siah1-transfected cells than in control cells (Fig. 6e). However, there was no significant difference in K63-polyubiquitination levels of AKT and YAP (Additional file 4: Figure S2D, E), suggesting that Siah1 promotes AKT and YAP K48-polyubiquitination levels and ubiquitin proteasome degradation. Taken together, these data indicated that Siah1 represses the occurrence and development of CRC by promoting the ubiquitylation of AKT and inhibiting the activity of the MAPK, PI3K-AKT and Hippo pathways.

\section{Discussion}

The tumorigenesis and progression of CRC is a complex process with multiple steps, factors and stages, accompanied by the activation of oncogenes and the inactivation of tumor suppressor genes. Chromosome 16q12-q13 is a region that is frequently deleted in a large variety of human tumors, such as prostate adenocarcinomas [38], primary breast cancers [39], hepatocellular carcinoma [40], ovarian cancers [41], Wilms' tumors [42] and colorectal carcinomas [43]. The Siah1 gene is located at 


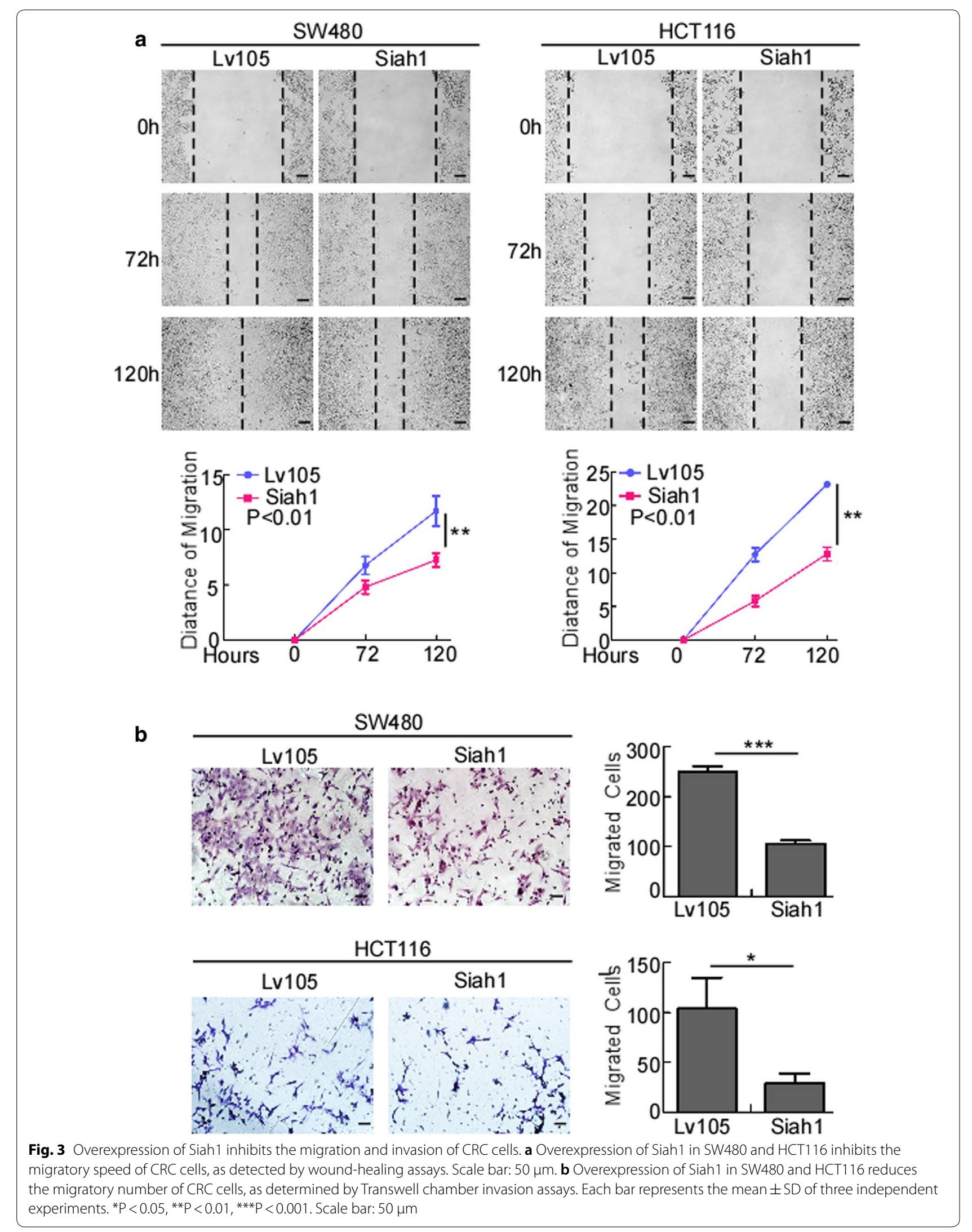



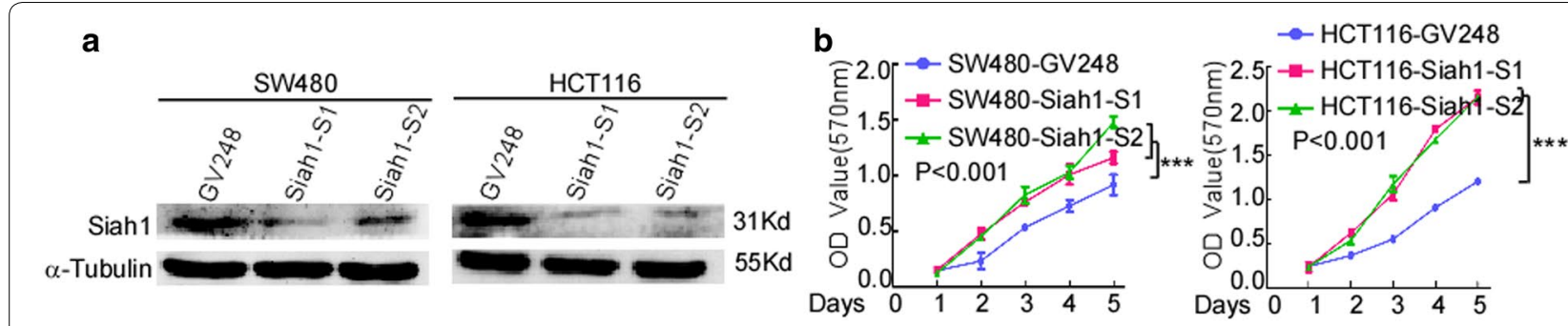

c
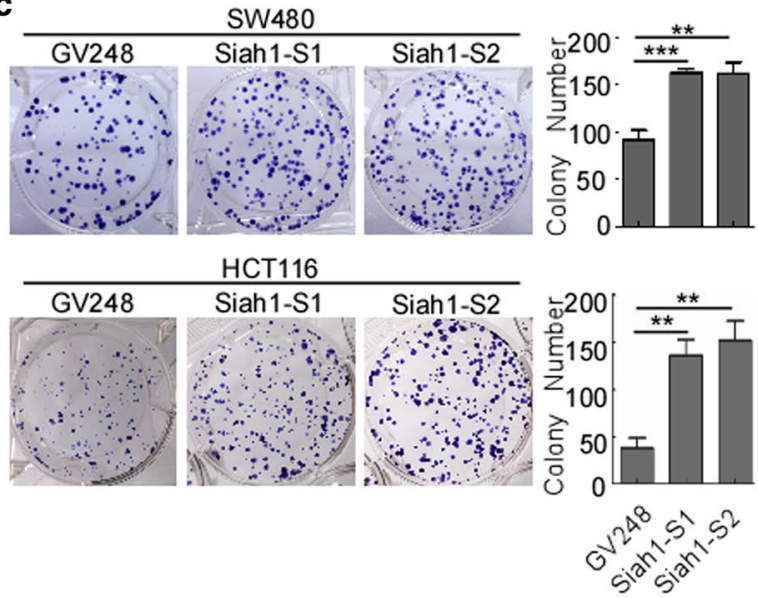

d
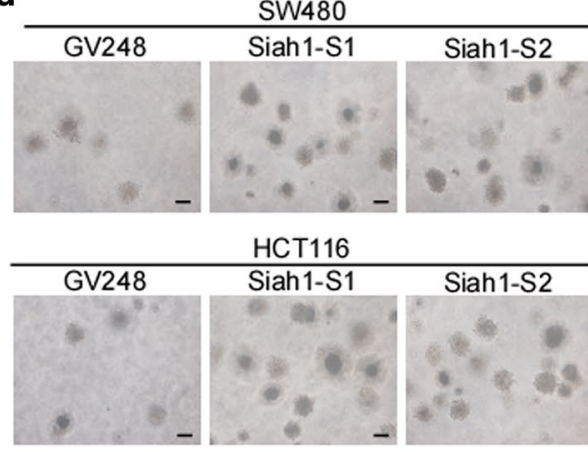

e
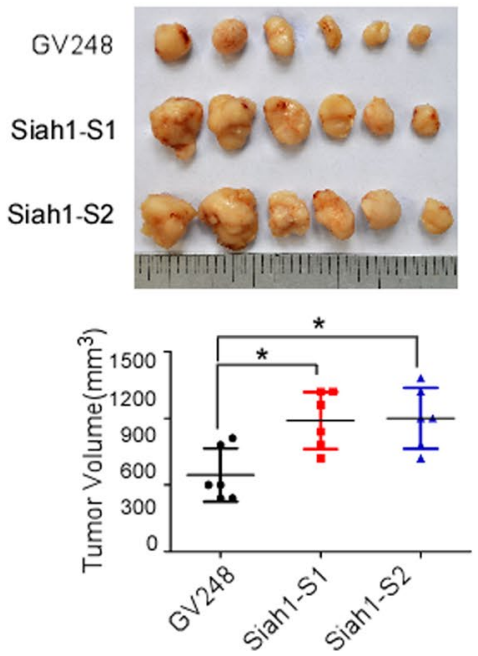

$\mathbf{f}$

$\begin{array}{lll}\text { H\&E } & \text { Siah1 } & \text { Ki-67 }\end{array}$
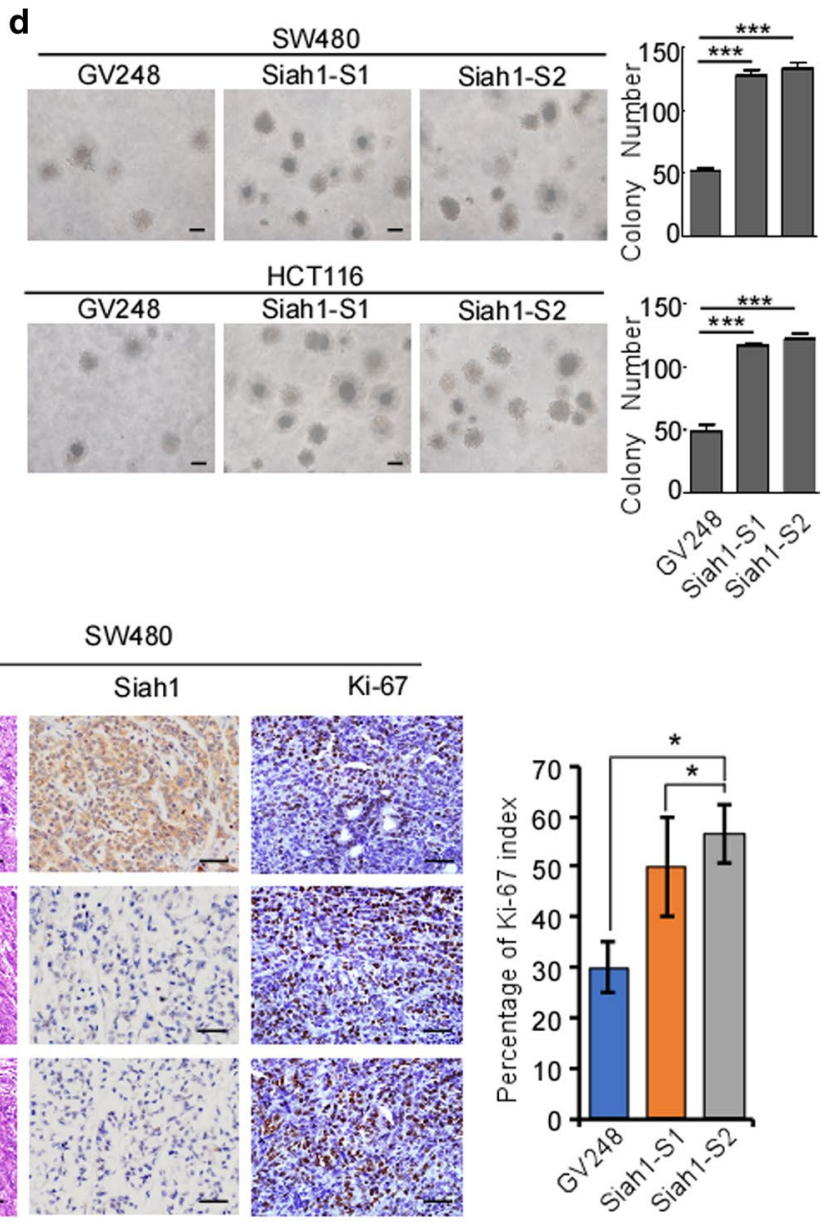

Fig. 4 Silencing of Siah1 promotes proliferation the of CRC cells. a RNAi-silencing of Siah1 in specific shRNA-transduced stable SW480 and HCT116 cells by Western blot. a-Tubulin was used as a loading control. b, c Knockdown of endogenous Siah1 promoted cell growth, as assessed by MTT assays (b) and colony formation assays (c). d Silencing of Siah1 promotes the growth ability of SW480 and HCT116, as determined by Soft agar assays. Colonies containing $>50$ cells were scored. Each error bar represents the mean \pm SD from3 independent experiments. Scale bar: $50 \mu m$. e, $\mathbf{f}$ SW480/GV248 and SW480/Siah1-shRNA cells $\left(2 \times 10^{6}\right)$ were injected in the hindlimbs of nude mice $(n=6)$. The volumes of tumor were measured on the indicated days. Panel upper shows tumors after inoculation. Data points are displayed as the mean tumor volumes \pm SD (lower panel). $\mathbf{f}$ The tumor histological sections were viewed H\&E staining and IHC staining using an antibody against Siah1 and Ki-67 (left), right panel shows average percentage of staining cells among the total cell as the Ki-67 index. Scale bar: $50 \mu \mathrm{m}$ 

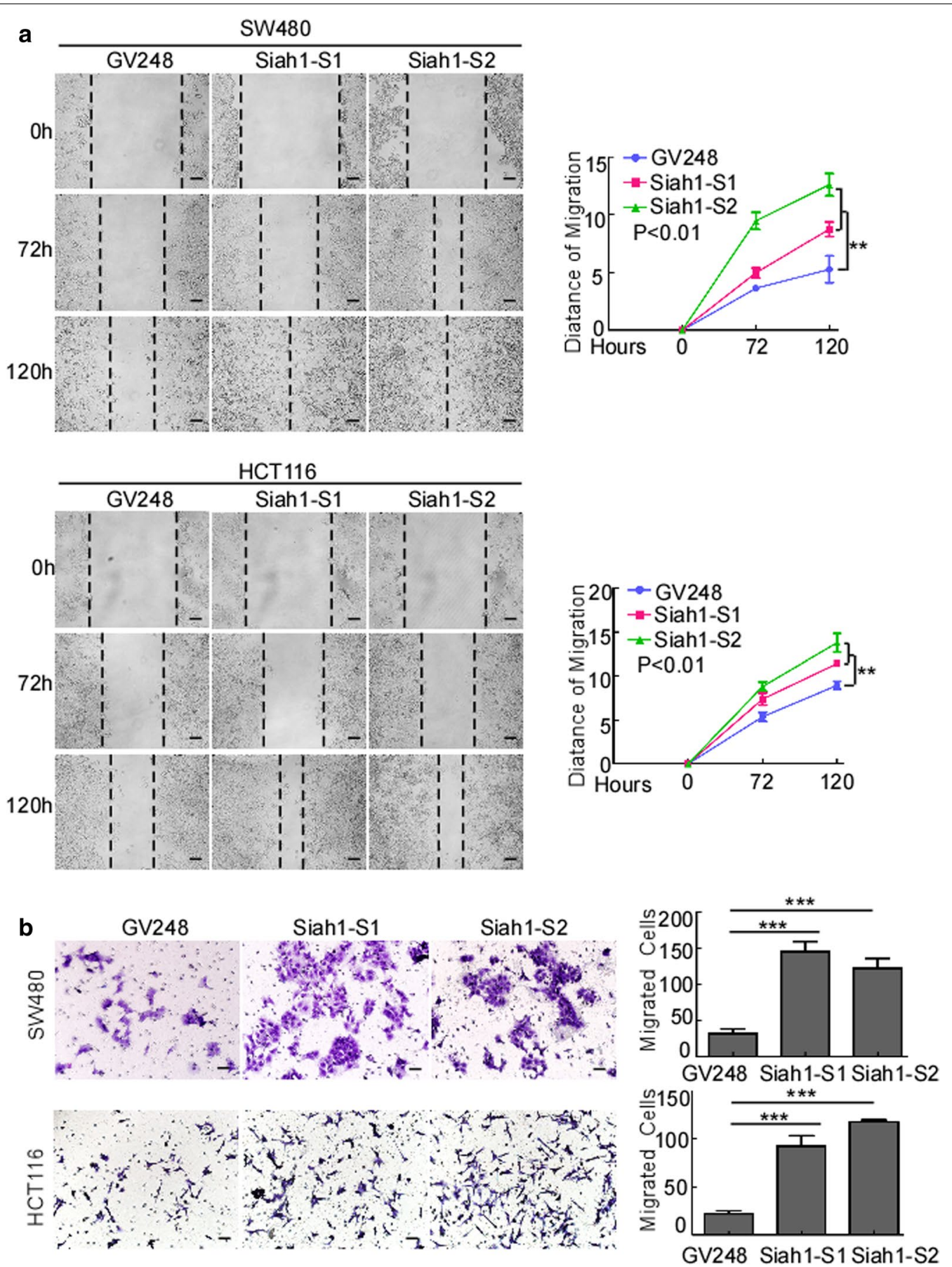

Fig. 5 Silencing of Siah1 promotes migration and invasion of CRC cells. a Depletion of Siah 1 in SW480 and HCT1 16 accelerates the migratory speed of CRC cells, as detected by wound-healing assays. Scale bar: $50 \mu \mathrm{m}$. b Silencing of Siah1 in SW480 and HCT116 increases the migratory number of CRC cells, as determined by Transwell chamber invasion assays. Each bar represents the mean \pm SD of three independent experiments. ${ }^{*} P<0.05$, ${ }^{* *} P<0.01$, ${ }^{* *} P<0.001$. Scale bar: $50 \mu \mathrm{m}$

16q12.1, and it is reported that the expression of Siah1 is often reduced or absent in various types of human cancers, including bladder cancer, lung cancer, breast cancer and hepatocellular carcinomas [17, 20, 44]. In this study, we found that Siah1 was downregulated in CRC, and low expression of the Siah1 protein was dramatically correlated to aggressive TNM staging and poor prognosis in CRC patients. 


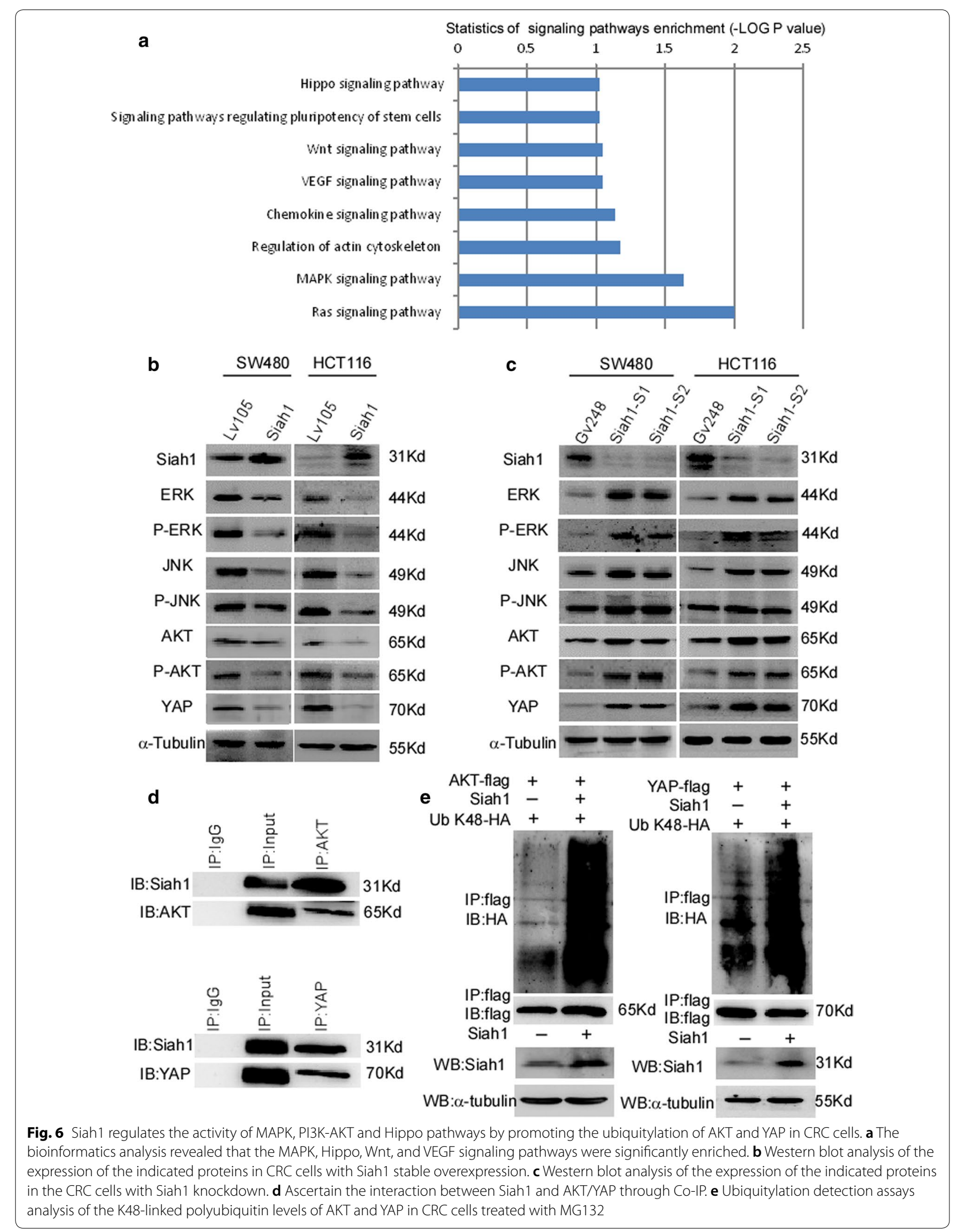


The Siah1 protein belongs to the highly conserved family of E3 ubiquitin ligases. Structurally, the Siah1 protein contains two zinc finger cytokine-rich domains and shares $77 \%$ identity with Siah-2 [14], but they have different substrate targets [13]. A large number of studies have shown that Siah1 plays a role as a tumor suppressor gene in the process of tumorigenesis and evolution. It has been documented that the overexpression of Siah1 in breast cancer cells and hepatocellular carcinoma cells induces apoptosis of cancer cells and inhibits the progression of cancer $[20,45]$. Our previous studies showed that miR-450-5p targeted the $3^{\prime}$-UTR (3'- Untranslated Region) of Siah1 to regulate the progression of colorectal cancer [10]. In the present study, we confirmed that exogenous overexpression of Siah1 suppressed CRC cells proliferation, invasion and tumor growth both in vitro and in vivo. Furthermore, this may also influence tumor cells' interactions with drugs through forming complexes with NMNT (Nicotinamide $\mathrm{N}$-methyltransferase) [46]. Exogenous knockout of Siah1 produced the opposite results. These findings indicate that Siah1 may serve as a tumor suppressor role in CRC and may be a novel potential prognostic factor of CRC.

Although Siah1 has been identified to regulate proliferation, invasion and tumor growth in CRC, the possible molecular mechanism remains largely unknown. As the results of biological information, we have confirmed that the MAPK, and Hippo pathways were significantly enriched in CRC with lower Siah1 expression. We also found that the P53_PATHWAY was significantly enriched upon Siah1 overexpression (Additional file 4: Figure S2B). It has been reported that the PI3K/AKT pathway was related to P53 pathway [47]. As the literature report, the Hippo signaling pathway can interact with the signaling pathways of NF- $\mathrm{kB}, \mathrm{MAPK}$ and other signals during bonebreaking cell formation. Especially in the Hippo-andMAPK signaling pathway, YAP/TAZ/TEAD can activate ERK, JNK, etc. to inhibit apoptosis [48]. So, we attempted to detected the key protein of these pathways. We demonstrated that Siah1 can regulate the activity of AKT, MAPK and Hippo signaling pathways in CRC cells.

More importantly, it has been documented that Siah1 facilitates ubiquitination and proteasome-dependent degradation of diverse substrate proteins with multiple functions. E3 ubiquitin ligase enzymes play a key role in target protein identification and the active regulation of the ubiquitination system. K48 and K63 ployUb chains have been widely studied. The polyUb chain modified protein with Lys 48 was degraded by the ubiquitin-proteasome pathway of the $26 \mathrm{~S}$ proteasome; polyUb K63 is

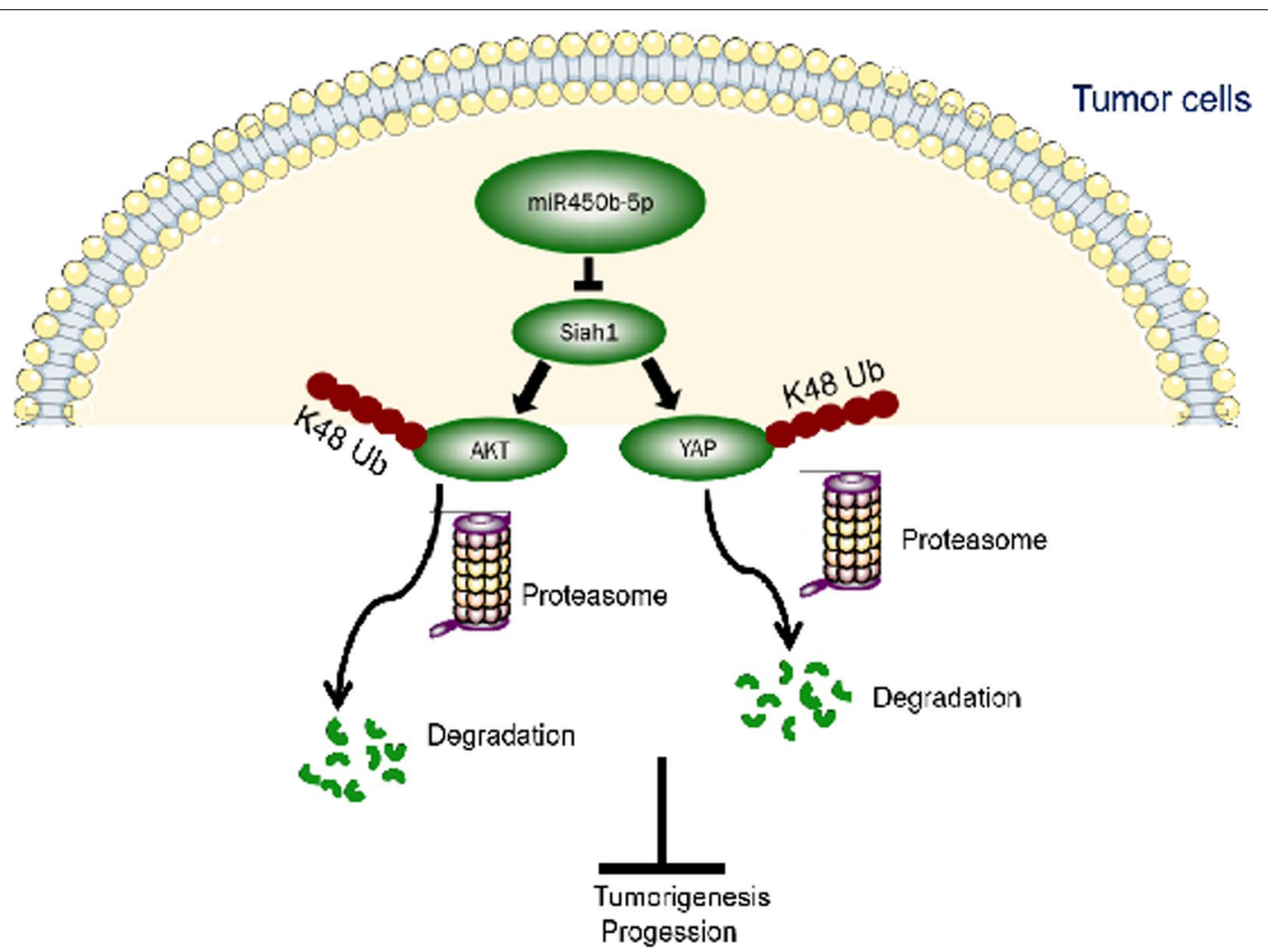

Fig. 7 Model: Siah1, downstream of miR450b-5p, promoting AKT and YAP ubiquitylation and proteasome degradation to regulate the activity of the PI3K-AKT and Hippo signaling pathways, ultimately leading to an aggressive CRC phenotype 
involved in the internalization and lysosomal degradation of membrane surface receptors $[49,50]$.

As the key molecule of PI3K-AKT signaling, AKT plays an oncogenic role in the development and progression of cancers, and it could also be a potential target for tumor therapy [51]. For example, TRAF6 catalyzed K63 poly-ubiquitylation level of AKT, contributing to the enhancement of AKT membrane localization and phosphorylation, thus promoting oncogenic AKT activation [52]. Another report showed that, activated AKT is a poly-ubiquitination target of MULAN (mitochondrial ubiquitin ligase activator of NF- $\mathrm{kB}$ ) and promotes p-AKT degradation [53]. We found was that Siah1 could interact with AKT and undergo PloyUb K48 chain ubiquitination in CRC cells. Related research shows that YAP, as one of the core molecules in Hippo signaling, was regulated by E3 ubiquitin ligases [54-56]. That is, it has been documented that $C K 1 \delta / \varepsilon$ recruits the SCF ( $\beta$-Trcp1) E3 ubiquitin ligase, which facilitates YAP ubiquitylation, ultimately leading to YAP degradation [55]. Our research also shows that Siah1 promotes YAP degradation in PolyUb K48 chains instead of K63. The results from our research demonstrated that Siah1 interacts with AKT and YAP, and it catalyzes the K48 poly-ubiquitylation and proteasome degradation of $\mathrm{AKT}$ and YAP in colorectal cancer cells.

\section{Conclusion}

Our study suggested that Siah1 is downregulated in CRC and might be a valuable prognostic marker of CRC progression. Dysregulation of Siah1 plays a vital role in promoting the development and progression of CRC, partially through promoting AKT and YAP ubiquitylation and proteasome degradation to regulate the activity of the PI3K-AKT and Hippo signaling pathways (Fig. 7). However, the mechanism of MAPK regulation by Siah1 requires further investigation.

\section{Supplementary information}

Supplementary information accompanies this paper at https://doi. org/10.1186/s12935-020-1124-3.

Additional file 1: Table S1. Relationship between clinicopathological features and Siah 1 expression in 170 CRC tissues. Table S2. Spearman correlation analysis between Siah1 and clinicopathologic features. Table S3. Sequences of shRNA primers.

Additional file 2: Additional materials and methods.

Additional file 3: Figure S1. (A) Average N/T ratio of Siah1 mRNA expression by RT-QPCR $(n=50)$. The expression of mRNA levels was normalized with B2M. Error bars represent mean \pm SD calculated from 3 parallel experiments. (B) Average N/T ratio of Siah 1 mRNA expression by RT-QPCR $(n=50)$. The expression of mRNA levels was normalized with $\beta$-actin. Error bars represent mean \pm SD calculated from 3 parallel experiments. (C) Representative expression of Siah 1 from score 0 to 3 in colorectal cancer patients. Scale bar: $50 \mu \mathrm{m}$.
Additional file 4: Figure S2. (A) RT-QPCR was performed on 50 pairs of CRC tissues. In 43 cases, the expression of Siah1 in normal tissues was higher than in paired tumor tissues. (B) The gene enrichment of CRC with Siah1 low expression by GSEA. (C) 8 CRC cell lines were measured the endogenous expression of Siah1, and choose the medium expression cell lines HCT116/SW480 to follow up subsequent functional study. Detection of K63-linked poly-ubiquitylation levels of AKT and YAP by ubiquitylation detection assays in CRC cells. (D) Ubiquitylation detection assays-based analysis of the K63-linked poly-ubiquitylation levels of AKT in CRC cells treated with MG132. (E) Ubiquitylation detection assays analysis of the K63-linked poly- ubiquitylation levels of YAP in CRC cells treated with MG132.

Additional file 5: Figure S3. (A-B) HCT116/LV105 and HCT116/Siah1 cells $\left(2 \times 10^{6}\right)$ were injected in the hindlimbs of nude mice $(n=6)$. The volumes of tumor were measured on the indicated days. Panel upper shows tumors after inoculation. Data points are displayed as the mean tumor volumes \pm SD (lower panel). (B) The tumor histological sections were viewed $\mathrm{H} \&$ E staining and $\mathrm{IHC}$ staining using an antibody against Siah1 and Ki-67 (left), right panel shows average percentage of staining cells among the total cell as the Ki-67 index. (C-D) The data showed proliferation experiment in vivo when Siah1 knockdown in HCT116 cell line. Scale bar: $50 \mu \mathrm{m}$. (E-F) The gray level bands showed the relaive Siah1, p-ERK/ERK, p-JNK JNK, p-AKT/AKT and YAP protein expression corresponding to Fig. 6b, c, which was used Quantity one Software.

\section{Abbreviations}

AKT: The serine-threonine protein kinase; APC: Adenomatous polyposis coli; C-Myb: C-MYB proto-oncogene; Co-IP: Co-immunoprecipitation; CRC : Colorectal cancer; DMSO: Dimethyl sulphoxide; ERK: Extracellular regulated protein kinases; IHC: Immunohistochemistry; JNK: c-Jun N-terminal kinase; KEGG: Kyoto Encyclopedia of Genes and Genomes; KRAS: Kirsten rat sarcoma viral oncogene homolog; MAPK: Mitogen-activated protein kinase 1; MG132: Carbobenzoxy-L-leucyl-L-leucyl-L-leucinal; MTT: 3-(4,5-Dimethyl-2-thiazolyl)2,5-diphenyl-2-H-tetrazolium bromide, thiazolyl blue tetrazolium bromide; MULAN: Mitochondrial ubiquitin ligase activator of NF-kB; NcoR: Nuclear receptor co-repressor; $\mathrm{p}$-AKT: Phosphorylated -AKT; PBS: Phosphate buffer saline; $p$-ERK: Phosphorylated-ERK; PI3K: Phosphatidylinositol 3-kinase; $p$-JNK: Phosphorylated -JUK; ployUb: Polyubiqutination; RIPA: Radio immunoprecipitation assay; RT-QPCR: Realtime-quantitative reverse transcription; SBD: Substrate binding domain; SDS-PAGE: Sodium dodecyl sulfate polyacrylamide gelelectrophoresis; Siah1: Siah E3 ubiquitin protein ligase 1; Taz: Tafazzin; TP53: Tumor protein p53; TRAF:TNF receptor associated factor; UTR: Untranslated region; VEGF: Vascular endothelial growth factor A; YAP: Yes associated protein.

\section{Acknowledgements}

Not applicable.

\section{Authors' contributions}

Conception and design: YD, YY, HJ. Development of methodology: HJ, YY, SYW. Acquisition of data (provided animals, acquired and managed patients, provided facilities, etc.): ZX, ZW, DD, ZZ, YZ, SJ. Analysis and interpretation of data (e.g., statistical analysis, biostatistics, computational analysis): ZX, ZW, DD, ZZ, DZ, L-JZ, MF, SC. Writing, review, and/or revision of the manuscript: HJ, YY, ZX, DD. Administrative, technical, or material support (i.e., reporting or organizing data, constructing databases): HJ, YY, YD, SYW. Study supervision: YD, YY, HJ. All authors read and approved the final manuscript.

\section{Funding}

This work was supported by the National Basic Research Program of China (973 program, 2015CB554002), the National key R\&D program of China (2017YFC1309002), the National Natural Science Foundation of China (81874194, 81702915, 81773101, 81472313, 81672886, 81472710), the Postdoctoral Science Foundation of China (2018 M633080), the Guangdong Provincial Natural Science Foundation of China (2017A030313583, 2016A030310395, 2017A030313463, 2016A030310392, 2017A030310117, 2017A030313707, 2016A030310394), the Science and Technology Innovation Foundation of Guangdong Higher Education (CXZD1016), and the Guangdong Medical Research Fund (A2017302). 


\section{Availability of data and materials}

All data generated or analyzed in this study are included in this published article. The datasets used during the current study are available from the corresponding authors.

\section{Ethics approval and consent to participate}

For the research purposes of using clinical materials, this study was approved by the Ethics Committee of Nanfang Hospital of Southern Medical University (A2017302), we also obtained with patient informed consent.

\section{Consent for publication}

Not applicable.

\section{Competing interests}

The authors declare that they have no competing interests.

\section{Author details}

${ }^{1}$ Department of Pathology, Nanfang Hospital and School of Basic Medical Science, Southern Medical University, Guangzhou 510515, China. ${ }^{2}$ Guangdong Provincial Key Laboratory of Molecular Tumor Pathology, Guangzhou, China. ${ }^{3}$ Department of Pathology, Shenzhen People's Hospital, Second Clinical Medical College of Jinan University, Shenzhen, Guangdong, China. ${ }^{4}$ Department of General Surgery, Nanfang Hospital, Southern Medical University, Guangzhou, China. ${ }^{5}$ Department of Pathology, Shaoyang Central Hospital, Affiliated Shaoyang Hospital of University of South China, Shaoyang, Hunan, China.

Received: 29 June 2019 Accepted: 25 January 2020

Published online: 13 February 2020

\section{References}

1. De Roock W, De Vriendt V, Normanno N, Ciardiello F, Tejpar S. KRAS, BRAF, PIK3CA, and PTEN mutations: implications for targeted therapies in metastatic colorectal cancer. Lancet Oncol. 2011;12(6):594-603.

2. Zhang L, Shay JW. Multiple Roles of APC and its therapeutic implications in colorectal cancer. J Natl Cancer Inst. 2017. https://doi.org/10.1093/jnci/ djw332.

3. Markowitz SD, Bertagnolli MM. Molecular origins of cancer: molecular basis of colorectal cancer. N Engl J Med. 2009;361(25):2449-60.

4. Huang D, Sun W, Zhou Y, Li P, Chen F, Chen H, et al. Mutations of key driver genes in colorectal cancer progression and metastasis. Cancer Metast Rev. 2018;37:173-87

5. Gwak J, Song T, Song JY, Yun YS, Choi IW, Jeong Y, et al. Isoreserpine promotes beta-catenin degradation via Siah-1 up-regulation in HCT116 colon cancer cells. Biochem Biophys Res Commun. 2009:387(3):444-9.

6. Hu G, Fearon AER. Siah-1 N-terminal RING domain is required for proteolysis function, and C-terminal sequences regulate oligomerization and binding to target proteins. Mol Cell Biol. 1999;19(1):724-32.

7. Xiao JH, Ghosn C, Hinchman C, Forbes C, Wang J, Snider N, et al. Adenomatous polyposis coli (APC)-independent regulation of beta-catenin degradation via a retinoid $X$ receptor-mediated pathway. J Biol Chem. 2003:278(32):29954-62.

8. Bruzzoni-Giovanelli H, Fernandez P, Veiga L, Podgorniak MP, Powell DJ, Candeias MM, et al. Distinct expression patterns of the E3 ligase SIAH-1 and its partner Kid/KIF22 in normal tissues and in the breast tumoral processes. J Exp Clin Cancer Res. 2010;29:10.

9. Chen Y, Lian Y, Ma Y, Wu C, Zheng Y, Xie N. LncRNA SNHG1 promotes $a-s y n u c l e i n$ aggregation and toxicity by targeting miR-15b-5p to activate SIAH1 in human neuroblastoma SH-SY5Y cells. Neurotoxicology. 2018:68:212-21.

10. Ye YP, Wu P, Gu CC, Deng DL, Jiao HL, Li TT, et al. miR-450b-5p induced by oncogenic KRAS is required for colorectal cancer progression. Oncotarget. 2016;7(38):61312-24.

11. Zhang L, Ma P, Sun L, Han Y, Li B, Mi X, et al. MiR-107 down-regulates SIAH1 expression in human breast cancer cells and silencing of miR-107 inhibits tumor growth in a nude mouse model of triple-negative breast cancer. Mol Carcinog. 2016;55(5):768-77.

12. Yan S, Li A, Liu Y. CacyBP/SIP inhibits the migration and invasion behaviors of glioblastoma cells through activating Siah1 mediated ubiquitination and degradation of cytoplasmic p27. Cell Biol Int. 2018;42(2):216-26.
13. Knauer SK, Mahendrarajah N, Roos WP, Kramer OH. The inducible E3 ubiquitin ligases SIAH1 and SIAH2 perform critical roles in breast and prostate cancers. Cytokine Growth Factor Rev. 2015;26(4):405-13.

14. MONA Nemani GL-C. HERIBERTO BRUZZONI-GIOVANELLIt, JEAN-PIERRE ROPERCH Activation of the human homologue of the Drosophila sina gene in apoptosis and tumor suppression. Proc Natl Acad Sci. 1996;93:9039-42.

15. Adam MG, Matt S, Christian S, Hess-Stumpp H, Haegebarth A, Hofmann TG, et al. SIAH ubiquitin ligases regulate breast cancer cell migration and invasion independent of the oxygen status. Cell Cycle. 2015;14(23):3734-47

16. Xu J, Zhang XZ, Zhang YJ, Li XM, Cai ZL, Li XM. Silencing of SIAH1 in SH-SY5Y affects a-synuclein degradation pathway. Int J Clin Exp Pathol. 2015;8(10):12885-92

17. Cho H-S, Kelly JD, Hayami S, Toyokawa G, Takawa M, Yoshimatsu M, et al. Enhanced expression of EHMT2 is involved in the proliferation of cancer cells through negative regulation of SIAH1. Neoplasia. 2011;13(8):676-84.

18. Yuan F, Chen X, Liu J, Feng W, Wu X, Chen S. Up-regulation of Siah1 by ethanol triggers apoptosis in neural crest cells through p38 MAPK-mediated activation of p53 signaling pathway. Arch Toxicol. 2017:91(2):775-84.

19. Brauckhoff A, Ehemann V, Schirmacher P, Breuhahn K. Reduced expression of the E3-ubiquitin ligase seven in absentia homologue (SIAH)-1 in human hepatocellular carcinoma. Verh Dtsch Ges Pathol. 2007;91:269-77.

20. Wen $Y Y$, Yang $Z Q$, Song $M$, Li BL, Yao XH, Chen $X L$, et al. The expression of SIAH1 is downregulated and associated with Bim and apoptosis in human breast cancer tissues and cells. Mol Carcinog. 2010;49(5):440-9.

21. Kim CJ, Cho YG, Park CH, Jeong SW, Nam SW, Kim SY, et al. Inactivating mutations of the Siah-1 gene in gastric cancer. Oncogene. 2004;23(53):8591-6

22. Yoshibayashi H, Okabe H, Satoh S, Hida K, Kawashima K, Hamasu S, Nomura A, Hasegawa S, Ikai I, Sakai Y. SIAH1 causes growth arrest and apoptosis in hepatoma cells through $\beta$-catenin degradation-dependent and -independent mechanisms. Oncol Rep. 2007;17:549-56.

23. Leung CO, Deng W, Ye TM, Ngan HY, Tsao SW, Cheung AN, et al. miR135 a leads to cervical cancer cell transformation through regulation of beta-catenin via a SIAH1-dependent ubiquitin proteosomal pathway. Carcinogenesis. 2014;35(9):1931-40.

24. Tanaka T, lino M. Sec6 regulated cytoplasmic translocation and degradation of p27 via interactions with Jab1 and Siah1. Cell Signal. 2014;26(10):2071-85

25. Ji L, Jiang B, Jiang $X$, Charlat $O$, Chen A, Mickanin C, et al. The SIAH E3 ubiquitin ligases promote $\mathrm{Wnt} / \mathrm{B}$-catenin signaling through mediating Wnt-induced Axin degradation. Genes Dev. 2017;31(9):904-15.

26. Garaycoechea J, Crossan G, Langevin F, Mulderrig L, Louzada S, Yang F, et al. Alcohol and endogenous aldehydes damage chromosomes and mutate stem cells. Nature. 2018:553(7687):171-7.

27. Jing Z, Sui X, Yao J, Xie J, Jiang L, Zhou Y, et al. SKF-96365 activates cytoprotective autophagy to delay apoptosis in colorectal cancer cells through inhibition of the calcium/CaMKIlgamma/AKT-mediated pathway. Cancer Lett. 2016;372(2):226-38.

28. Chen L, Tang J, Feng Y, Li S, Xiang Q, He X, et al. ADAMTS9 is silenced by epigenetic disruption in colorectal cancer and inhibits cell growth and metastasis by regulating Akt/p53 signaling. Cell Physiol Biochem. 2017:44(4):1370-80.

29. de Sousa N, Rodriguez-Esteban G, Rojo-Laguna Jl, Salo E, Adell T. Hippo signaling controls cell cycle and restricts cell plasticity in planarians. PLoS Biol. 2018:16(1):e2002399.

30. Jiao HL, Ye YP, Yang RW, Sun HY, Wang SY, Wang YX, et al. Downregulation of SAFB sustains the NF-kappaB pathway by targeting TAK1 during the progression of colorectal cancer. Clin Cancer Res. 2017;23(22):7108-18.

31. Cui YM, Jiang D, Zhang SH, Wu P, Ye YP, Chen CM, et al. FOXC2 promotes colorectal cancer proliferation through inhibition of $\mathrm{FOXO} a$ and activation of MAPK and AKT signaling pathways. Cancer Lett. 2014;353(1):87-94

32. Wang $Y, X u H$, Jiao $H$, Wang $S$, Xiao Z, Zhao Y, et al. STX2 promotes colorectal cancer metastasis through a positive feedback loop that activates the NF-kappaB pathway. Cell Death Dis. 2018;9(6):664.

33. Wang S, Xiao Z, Hong Z, Jiao H, Zhu S, Zhao Y, et al. FOXF1 promotes angiogenesis and accelerates bevacizumab resistance in colorectal cancer by transcriptionally activating VEGFA. Cancer Lett. 2018;439:78-90. 
34. Wang S, Yan S, Zhu S, Zhao Y, Yan J, Xiao Z, et al. FOXF1 Induces epithelialmesenchymal transition in colorectal cancer metastasis by transcriptionally activating SNAl1. Neoplasia. 2018;20(10):996-1007.

35. Ye YP, Jiao HL, Wang SY, Xiao ZY, Zhang D, Qiu JF, et al. Hypermethylation of DMTN promotes the metastasis of colorectal cancer cells by regulating the actin cytoskeleton through Rac1 signaling activation. J Exp Clin Cancer Res. 2018;37(1):299.

36. Dowsett M, Nielsen TO, A'Hern R, Bartlett J, Coombes RC, Cuzick J, et al. Assessment of Ki67 in breast cancer: recommendations from the International Ki67 in Breast Cancer working group. J Natl Cancer Inst. 2011;103(22):1656-64

37. Tripathi MK, Deane NG, Zhu J, An H, Mima S, Wang X, et al. Nuclear factor of activated T-cell activity is associated with metastatic capacity in colon cancer. Cancer Res. 2014;74(23):6947-57.

38. Latil A, Cussenot O, Fournier G, Driouch K, Lidereau R. Loss of heterozygosity at chromosome $16 \mathrm{q}$ in prostate adenocarcinoma: identification of three independent regions. Cancer research. 1997;57:1058-62.

39. Bièche I, Lidereau R. Genetic alterations in breast cancer. Genes Chromosom Cancer. 1995;14:227-51.

40. Boige V, Laurent-Puig P, Fouchet $P$, Fléjou JF, Monges G, Bedossa P, Bioulac-Sage P, Capron F, Schmitz A, Olschwang S, Thomas G. Concerted nonsyntenic allelic losses in hyperploid hepatocellular carcinoma as determined by a high-resolution allelotype. Cancer Res. 1997;57:1986-90.

41. Sato T, Saito H, Morita R, Koi S, Lee JH, Nakamura Y. Allelotype of human ovarian cancer. Cancer Res. 1991;51:5118-22.

42. Grundy PE, Telzerow PE, Breslow N, Moksness J, Huff V, Paterson MC. Loss of heterozygosity for chromosomes $16 \mathrm{q}$ and ip in Wilms' tumors. Cancer Res. 1994;54:2331-3.

43. Bardi G, Johansson B, Pandis N, Mandahl N, Mitelman F, Heim S, BakJensen E, Lindström C, Törnqvist A, Frederiksen H, Andrén-Sandberg Å. Cytogenetic analysis of 52 colorectal carcinomas-non-random aberration pattern and correlation with pathologic parameters. Int J Cancer. 1993:55:422-8.

44. Matsuo K, Satoh S, Okabe H, Nomura A, Maeda T, Yamaoka Y, et al. SIAH1 inactivation correlates with tumor progression in hepatocellular carcinomas. Genes Chromosom Cancer. 2003;36(3):283-91.

45. Zhao J, Wang C, Wang J, Yang X, Diao N, Li Q, et al. E3 ubiquitin ligase Siah-1 facilitates poly-ubiquitylation and proteasomal degradation of the hepatitis B viral X protein. FEBS Lett. 2011;585(19):2943-50.
46. Bach DH, Kim D, Bae SY, Kim WK, Hong JY, Lee HJ, et al. Targeting nicotinamide $\mathrm{N}$-methyltransferase and miR-449a in EGFR-TKI-resistant non-smallcell lung cancer cells. Mol Therapy Nucleic Acids. 2018;11:455-67.

47. Abraham AG, O'Neill E. PI3K/Akt-mediated regulation of $\mathrm{p} 53$ in cancer. Biochem Soc Trans. 2014:42(4):798-803.

48. Yang W, Han W, Qin A, Wang Z, Xu J, Qian Y. The emerging role of Hippo signaling pathway in regulating osteoclast formation. J Cell Physiol. 2018;233(6):4606-17

49. Pickart CM, Fushman D. Polyubiquitin chains: polymeric protein signals. Curr Opin Chem Biol. 2004;8(6):610-6.

50. Sliter DA, Aguiar M, Gygi SP, Wojcikiewicz RJ. Activated inositol 1,4,5-trisphosphate receptors are modified by homogeneous Lys-48- and Lys63-linked ubiquitin chains, but only Lys-48-linked chains are required for degradation. J Biol Chem. 2011;286(2):1074-82.

51. Brown JS, Banerji U. Maximising the potential of AKT inhibitors as anticancer treatments. Pharmacol Ther. 2017;172:101-15.

52. Yang WL, Wang J, Chan CH, Lee SW, Campos AD, Lamothe B, et al. The E3 ligase TRAF6 regulates Akt ubiquitination and activation. Science. 2009;325(5944):1134-8.

53. Bae $\mathrm{S}$, Kim SY, Jung JH, Yoon $Y$, Cha HJ, Lee $H$, et al. Akt is negatively regulated by the MULAN E3 ligase. Cell Res. 2012;22(5):873-85.

54. Toloczko A, Guo F, Yuen H, Wen Q, Wood S, Ong Y, et al. Deubiquitinating enzyme USP9X suppresses tumor growth via LATS kinase and core components of the hippo pathway. Cancer Res. 2017;77(18):4921-33.

55. Zhao B, Li L, Tumaneng K, Wang C, Guan K. A coordinated phosphorylation by Lats and CK1 regulates YAP stability through SCF(beta-TRCP). Genes Dev. 2010;24(1):72-85.

56. Liu C, Zha Z, Zhou X, Zhang H, Huang W, Zhao D, et al. The hippo tumor pathway promotes TAZ degradation by phosphorylating a phosphodegron and recruiting the SCF $\{$ beta\}-TrCP E3 ligase. J Biol Chem. 2010;285(48):37159-69.

\section{Publisher's Note}

Springer Nature remains neutral with regard to jurisdictional claims in published maps and institutional affiliations.

Ready to submit your research? Choose BMC and benefit from

- fast, convenient online submission

- thorough peer review by experienced researchers in your field

- rapid publication on acceptance

- support for research data, including large and complex data types

- gold Open Access which fosters wider collaboration and increased citations

- maximum visibility for your research: over 100M website views per year

At BMC, research is always in progress.

Learn more biomedcentral.com/submissions 